\title{
Contextualizing Classical and Contemporary Management Theories in African Society
}

\author{
Basuo Bio Kuroakegha ${ }^{1}$ Don-Solomon, Amakiri ${ }^{2 *}$ \\ 1.Department of Management ,Faculty of Management Sciences,Niger Delta University \\ Amassoma \\ 2.Department of Office and Information Management, Faculty of Management Sciences \\ Niger Delta University Amassoma
}

\begin{abstract}
This paper examined the contextualization of contemporary management theories in African society. The paper is theoretical and reviewed literature which bordered on the extent to which classical theories based on Western historical ideologies can be considered appropriate and effective within African organizations and work settings. The paper contributes by approaching this issue from the perspective of a theory-A method of research which not only recognizes the uniqueness of the African context but also indicates that the application of theories or formulation of such must appreciate the prevailing challenges and features which characterize the world and existence of the African. In conclusion, the paper affirms that Africans have a distinct way of life and belief systems which any theoretical appropriation should appreciate and adapt its models to accommodate.
\end{abstract}

Keywords: Management theory, African context, research method, theory-A

DOI: $10.7176 / \mathrm{IKM} / 9-7-05$

Publication date: August $31^{\text {st }} 2019$

\section{Introduction}

The tenets and ideologies which serve as premise and frameworks for theoretical postulations are such that are drawn from or driven by contextual experiences and exchanges. Weihrick \& Koontz (2003) argued that these experiences are considerably universal and as such allow for the generalization of their related theories. Moreso, Ahiauzu, (1999); Ifechukwu, (2010); George, Kuye \& Onokala, (2012) hold strong position which suggest that contexts contain and offers unique and distinct experiences. This debate stems primarily from a philosophical position on the epistemological features and attributes of societies and the extent to which they can be described as different, as well as the extent to which theories generated within other contexts can be appropriated to others with clearly different cultures and work-life experiences.

Western Classical and contemporary management theories are presently dominant in management research and their assumptions provide the core assumptions of organizational behaviour even within most African countries. This is partly due to the imperialistic and colonial activities of the West which for more than five decades, successfully infused and engrained their philosophies and ideals on some African Nations. These ideals, although clearly recognized as foreign or alien, have however served as the base and structure upon which learning and knowledge development are premissed on. In this vein, some present-day scholars Ahiauzu, (1999); George, et al, (2012) have challenged these structures as contradictory to the African thought system. Their position is that there is a substantial difference in the Western and African context and that these ideals are problematic and have rather negated the progress of the African management thoughts.

This paper reviews content concerned with the growing debate on the contextualization of Western originating classical management theories within African societies. The paper contributes to the growing body of research on the topic as it provides a unique approach towards addressing the apparent disparities in Western based management theories and African societies hinged on the theory of type-A research methodology put forward by Ahiauzu (1999).

Its point of departure therefore stems primarily from the position it offers in addressing the evident challenges and work-related problems due to the observed inconsistencies presented by scholars which identify the poor development and growth of African societies and their economic lags as resulting from the unsuitability of economic, political and management ideologies and theories, considered as borrowed and alien to their thought system.

\section{Literature Review}

\section{Theories and context}

Theories are developed based on facts and form the praxis through which problems are addressed. They provide prescriptions or descriptions with regards to relationships, manifestations and exchanges. In management, theories are formulated principally to address work related challenges bordering mostly on relationships, performance and productivity. As such, the ideologies and overriding assumptions of a good theory is premised on providing solutions to organizational emergent challenges and predicting outcomes of effects and 
relationships within the organization (Woolf, 1965).

Notable scientific and classical management theories such as those of Frederick Taylor, Henri Fayol, and Max Weber were all developed based on actual first-hand experiences and the accumulation of knowledge within particular work settings and social frameworks. The application of a theory within a system is therefore hinged first on its emergence from such a system or its contextual appropriability to the system (Hafsi \& Farashahi, 2005; Hofstede, 1991).

In this vein, one may argue that one of the problems associated with most African work settings can be traced to their adoption of theoretical models which offer significantly dissimilar options or solutions to African contextual issues. Ahiauzu (1999) observed that the African man is defined by a set of historical beliefs and values which he brings along with him to the workplace and through whose lens he perceives and interacts with his fellow workers and colleagues at the workplace.

Drawing from the frameworks provided by most Western based classical management theories, one finds a prevailing emphasis on authority and productivity. As such an underlying focus on developing and strengthening structures and ensuring goal achievement. However, within most African work settings some other factors interfere with the exchanges at the workplace. These as observed by Ahiauzu (1999) and Ifechukwu (2010) comprise of factors such as age, ethnicity, family ties and cultural values.

From the foregoing, it is evident that for a theory to be adopted and effectively applied within any context, there are three major prerequisites that must be satisfied, these are:

i. The theories must emanate from the contextual issues and apparent gaps in the organization's domain. That is to say, the statements and ideas behind the theory should be as a result of actual issues and evident challenges within its context which it is developed to solve or provide solutions for

ii. The adoption or effectiveness of theories can also apply to work settings and contexts which share significant attributes in terms of culture, thought patterns, and ethnic diversity with that from where such theories were developed

iii. Theories should be fluid with models adapted in such a way that incorporates features and attributes not originally accounted but emerging in the course of its application within contexts that have certain distinctive qualities and characteristics which differentiate it from the context whereon such theories were originally formulated

\section{The African context}

Social research in Africa draws mainly from European philosophies. This is as most sociological research in and on Africa, has rather relied on examining Africa through foreign lens and assumptions. Theory formulation has therefore tended to impose on the African, generalizations procured and deducted from dissimilar contextual frameworks and thought-systems, implying possible flaws in the assertions about the African workman, his behaviour and his experiences at the workplace. This event follows a socio-historical pattern of cultural and economic development with roots deeply entrenched in the acculturation orientations of Africans following the post-colonization era.

Recent empirical studies Harkink \& Tijhuis, (2006); Bornman, Botha \& Harinarain, (2012) indicate varying work-related outcomes on same variables given distinct socio-cultural contexts, thus implying possible mitigation from extraneous, contextual based factors or variables. Hence, there is therefore the need to re-assess prevailing social research methods and their context as well as universal relevance especially as regards social research outcomes in Africa.

In addressing this observed disparity between research methods and their contextual settings, Ahiauzu (1999) argued that the belief system of Africans holds significant implications for their attitudes and behaviour. He noted that such belief systems form an integral feature which characterizes their way of life and impacts on their stance at the workplace. A good example of this is that most African workers tend to blame their misfortunes at work on other extraneous factors such as gods or ancestral spirits. Thus, in building theories about the African workman, such should begin with a phenomenological approach towards understanding the African. It should seek to "see through his eyes" and "hear through his ears". Therefore, rather than seeking to understand the African worker from "heaven to earth", it should examine him from "earth to heaven" (Marx, cited in Ahiauzu and Asawo, 2016).

Airoboman and Asekhauno (2012) in their study, commended the various pro-African philosophers and epistemologists for their zeal in attempting to expand the African knowledge scope, but argue that much of their advocacy is misguided and out of place. The push for an African form of epistemology or knowledge is one based on the assumption of the existence of a European epistemology, an assumption which Airoboman and Askhauno opine is in erroroneous. This is as there is no single, unified or agreed upon European sociological method or epistemology but rather individual European philosophers with divergent and opposing positions about knowledge. Further, Airoboman and Askhauno observed that much of the language and ideas which characterize the so-called African epistemology are borrowed and premised on European literature. Concepts 
like the Ubuntu (Tutu, 2013) which describes humanity through its philosophy of "I am because we are" resonates with Sartre's existential philosophy that man is a being in the world and a being because of others, the Senghorian proclamation that "I smell, I dance the other, I am" is also a literary reflection of Cartesian's "I think, therefore I am".

In their study, Airoboman and Askhauno (2012) stated that philosophies cannot and should not be classified as European or African because it is situated in that culture but rather because it is put forward by a philosopher of that culture, Udefi's (2014) contrasting view upholds the argument that philosophies are and should be considered products of their peculiar contexts. According to Udefi, the thought-system and life of the African is highly spiritual and mystified. In his everyday life he ascribes meanings and interpretations to objects and events based on his highly superficial stance about reality. This agrees with the arguments of Ahiauzu (1999) Mbiti (1969) and Senghor (1964) that the African is intimately involved with his reality, and unlike the European, he makes no clear-cut distinction between himself and his external world but rather in his participation with the external, ascribes meanings and interpretations based on his traditional belief systems to the objects which characterize his external world. Therefore, a comparison of Cartesian "I think, therefore I am" and Senghor's "I smell, I dance the other, I am" is one based on the suitability of such to context. Where the former simply captures a generalized statement of being, the latter applies more to the African and his sensual participation in the object (Udefi, 2014).

In investigating the behaviour of the African within the workplace, Ahiauzu (1999) argues that it is imperative that such investigations must begin with an understanding of the African's traditional context. This is as there is a strong link between tradition and modernity to the African man and to draw facts about one aspect would invariably imply concluding about features of the other. In his African Industrial Man, Ahiauzu (1999) clearly outlines the steps and processes which he advocates for his type-A research methods. Specifying criteria for problem formulation, research questions and sampling techniques. However, as earlier noted, this method shares similar characteristics with most ideographic studies, most notably, the grounded methodology, the primary distinction being its identification of a socio-cultural and socio-relational boundary within which the research problems are based and within which the theories attained apply.

In an earlier observation, we noted the inadequacies and flaws associated with perceptions of Africa through "foreign lens" and the apparent disconnect between observer and the object which has led to the crude labels and base descriptions of Africans as primitive and barbaric (Pritchard, 1965, cited in Ahiauzu \& Asawo, 2016). However, before the advent of colonial administration, Ahiauzu and Asawo (2016) argue that Africans had well established and effective public administrative systems which were administered through recognized chiefs, town heads and kings. This is evident from historical records which prove the existence of great ancient walled cities in Africa with various towns and villages well governed and organized into social classes comprising mainly of royalty, the king makers or elders, the populace and then the village army which most often involved all able-bodied young male adults (Ahiauzu \& Asawo, 2016).

Given the arguments presented, one could interject at this point that it is possible that most of the current problems and challenges experienced by Africans with regards to organizational leadership, workplace cohesiveness and workers' attitude, could stem primarily from the adoption and application of "foreign solutions" to "local problems". This is as a result of the ongoing treatment and reliance of research in African on foreign based theories of behaviour as "panacea" for all forms of organizational behaviour related ills or issues including those premised within the obviously unique socio-contextual and socio-cultural confines of Africa (Ahiauzu, 1999).

This imposition of structural values and relational frameworks upon the African is one which not only distorts his traditional configurations and value system, but also attempts to reorient him with a mind-set much unsuited for the nature of his long accustomed and imbibed mode of operating within his traditional social networks, especially those outside his work environment such as family and kinsmen. Schutz (1974, cited in Ahiauzu \& Asawo, 1999) argued that the sciences that would interpret and explain human action and thought must begin with a description of the foundational structures of what is pre-scientific, the reality which seems self-evident to men remaining within the natural attitude. The reality is the everyday life-world.

This view as noted by Ahiauzu and Asawo (2012), offers an emphasis on the foundational structure of the African in truly grasping the behavioural tendencies of the African. It is clear from the argument above that such foundational structures as peculiar to the African are unique and quite distinct from what may comprise or compose of a foundational structure to the European. Another similar observation underscoring the application of foreign precepts to African socio-contextual frameworks especially as it relates to its educational content is put forward by Kaputa (2011).

Kaputa (2011) noted that African Education has been guided by inappropriate knowledge systems for too long and proceeds to proffer what He terms, a suitable or appropriate epistemology in African Education. But what really is its definition? What is its philosophical basis and how can the whole argument be put in an African perspective? Can the historical background of Africa be analysed revealing the "inappropriate" philosophies or 
theories at play then and now; what African traditional philosophies and theories should the debate focus on with the aim of selecting appropriate epistemologies, which can be used in African education and work settings.

Similarly, Brown's (2004) observed that unless one is intimately familiar and well acquainted with the ontological commitments of a culture, it is very difficult to value, appreciate or even understand those commitments. Implying that to really understand the actions, behaviour and expectations of the African, it is important that one first comes to terms with the African's epistemological position or approach to knowledge.

Thus, the applicability of methods of inquiry and knowledge acquisition should first aim at attending to the nature and experiences of the object itself, sorting out its configurations through a careful follow-up and in-depth analysis through actual participation in the life-world and thereafter, the summations and theoretical conceptualizations specific to the context wherein the problem or issue of interest originated from.

\section{The Type-A Research}

Ahiauzu (1999) describes the type-A research method as that which studies and theorizes on the African workman's behaviour through the adoption of the existential phenomenology. The method is one which attempts to acquire knowledge about the subject by sharing in his world, experiencing his materialistic conditions and allowing events to unfold during the process of investigation. Ahiauzu further distinguishes between the Type-A method and the grounded theory (Glaser \& Strauss, 1968 cited in Ahiauzu, 1999) both of which share the characteristic of emergent knowledge and theories premised on qualitative data.

In his distinction, Ahiauzu (1999) argued that whereas the grounded theory ended with conclusions premised on the data, the type-A however yet progresses to another stage, one where the results are applied to the unique contextual frameworks and socio-cultural platforms upon which the African and his workplace are operational and interrelate. Hence, the actual emphasis of this method is the applicability of its theories to a context (African) one might argue, suits it and within which its assertions are compatible with existing social facts and relations.

In a model which he argues can be utilized in determining the capacity of a motivational technique in stimulating or motivating Nigerian workers or groups within the organization, Ahiauzu (1999) states that most managers and social scientist fail to realize that the Africa worker, no matter the amount of time spent at work, still has a life to live outside the walls of the organization. The model which he stresses serves the purpose of harnessing various possible workers behavioural antecedents at the workplace, is a product of his investigation of the motivational factors of certain Yoruba and Ibo Nigerian organizations. The model is presented as:

$$
\mathrm{MP}_{\mathrm{t}}=f\left(\mathrm{WC}_{\mathrm{t}}\right)=f\left(\mathrm{~S}_{\mathrm{w}}, \mathrm{A}_{\mathrm{w}}, \mathrm{D}_{\mathrm{w}}, \mathrm{E}_{\mathrm{w}}, \mathrm{T}_{\mathrm{w}}, \mathrm{U}_{\mathrm{w}}, \mathrm{Y}_{\mathrm{w}}, \mathrm{R}_{\mathrm{w}}\right)
$$

Where:

$\mathrm{MP}_{\mathrm{t}}=$ Motivational potential of technique

$\mathrm{WC}_{\mathrm{t}}=$ Worker's perception of technique

$\mathrm{S}_{\mathrm{w}}=$ Sex and marital status of worker

$A_{w}=$ Age of worker or age of the structure of the workplace

$\mathrm{D}_{\mathrm{w}}=$ Distance between workers real home and workplace

$\mathrm{E}_{\mathrm{w}}=$ Ethnic or tribal group of worker in relations to that of manager

$\mathrm{T}_{\mathrm{w}}=$ Type of work the worker does

$\mathrm{U}_{\mathrm{w}}=$ Educational level of worker

$\mathrm{Y}_{\mathrm{w}}=$ Length of years in wage or salary employment

$\mathrm{R}_{\mathrm{W}}=$ Religion of the worker and the level of fanaticism

The above model provides an overview of some of the factors which as earlier noted significantly distinguishes the African worker and his frame of mind from that of the Western. In this vein, the African is considered as embodying several core traditional and cultural tenets which define his behaviour and his perception of work. His perception of work is considered as secondary to other factors which define his being and functionality within the community.

\section{Conclusion}

In conclusion, this theoretical discourse revealed a growing scholarly clamour for a shift in the current management theoretical applications and research methods practiced across Africa, which not only neglects the evident peculiarities of the African socio-contextual factor, but also ignores the African's heightened emotional and traditional life world. One finds from the review, apparent references to differing emotional states between the European and the African with regards to the external world. Whereas the European is considered as less emotional, more laid back and objective about his environment, the African is highly emotional and considers himself a part and parcel of everything around him.

The study further reveals substantial support for the development of theories, which according to Ahiauzu (1999) are premised on his type-A research method, which encapsulates universal techniques such as population, sampling and data analysis, but however, takes cognizance of the localization of the problem and the 
crystallization of such into research questions specifically tuned to peculiar socio-cultural and socio-contextual needs and challenges. Hence, it is imperative that research methods be modified to the extent that although they yet contain and maintain universal precepts and scientific benchmarks, they should also be relevant and applicable to unique contextual and societal frameworks and social facts.

Moreso, the study recommends a systematic approach towards structuring research methods such as offered by the Type- A method which methodologically incorporates various facets of the African into a holistic picture of him at the workplace. These facets as we earlier pointed out, comprising primarily of demographic factors such as age, perceptions of work technique, marital status, religion etc. should be harnessed in such a way that yields valuable and reliable data and knowledge about his motivational factors such as: needs, desires, ambitions, fears and objectives in the development of suitable and applicable theories.

\section{References}

Ahiauzu, A.I \& Asawo, S.P (2016). Advanced social research methods. A CIMRAT publication.

Ahiauzu, A.I (1999). The African Industrial Man. CIMRAT publications.

Airoboman, F. A \& Asekhauno, A.A (2012). Is there an 'African' epistemology? JORIND 10 (3), 13 - 17

Bornman, C., Botha, M. \& Harinarain, N. (2012). Assessment of organisational culture in the South African construction industry. In: Pearl, R.G. \& Verster, J.J.P. (eds), Proceedings of the ICC, International Cost Engineering Council 8th World Congress, Quest for Quality: Professionalism in Practice, 23-27 June. Durban, South Africa, pp. 32-41.

Brown L.M., (2004). Understanding and Ontology in Traditional African Thought" in Lee M. Brown, (ed.), African Philosophy: New and Traditional Perspectives, (Oxford: Oxford University Press. 158-178

George, O.J., Kuye, O.L., and Onokala, U.C. (2012). 'Culture and Management Practices are Siamese Twins: The Case of Employee Relations Practice in Nigeria (Cadbury Nigeria plc) and the United Kingdom (Cadbury Worldwide UK). Business and Management Review 3(2): 9-22.

Glaser, B. G., \& Strauss, A. L. (1968). Time for dying. Chicago, IL: Aldine Publishing

Hafsi, T. and Farashahi, M. (2005). Applicability of Management theories to developing countries: a synthesis. 45(4).

Harkink, E. \& Tijhuis, W. (2006). Innovation strategy: Choosing a central or decentral approach in construction business? In: Proceedings Acta Structilia 2013: 20(1)

Hofstede, G. (1991). Cultures and organisations: Software of the wind. New York, NY: McGraw-Hill.

Hofstede, G. H. (1980). Culture's consequences: International differences in work-related values, London: Saye Publications

Ifechukwu, J.A.O. (2010). African Approach to Management: Notes toward a Theory: Lagos, p.9.

Kaputa, T.M (2011). An appropriate epistemology in African education. Zimbabwe International Journal of Open \& Distance Learning. 1(2) 67 - 74.

Mbiti, J.S. (1969). The Concept of God in Africa, London: S.P.C.K.

Senghor, L. S. (1964). On African socialism. London: Fredrick A Praeger Publishers

Tutu, D., 2013, 'What about justice? Arguments for restorative justice', in J. Allen (ed.), God is not a Christian: Speaking truth in times of crisis, pp. 37-47, Rider, London.

Udefi, A. (2005). Theoretical foundations for an African epistemology. In R. A. Akanmidu (Ed.), Footprints in philosophy. Ibadan: Hope Publications Ltd.

Watson, W. E., Kumar, K., \& Michaelsen, L. K. 1993.Cultural diversity's impact on interaction process and performance: comparing homogeneous and diverse task groups. Academy of Management Journal, 36: 590-602.

Weihrick, H. and Koontz, H. (2003) Management: A Global Perspective, McGraw-Hill Inc., Tata, 10th edition. Woolf, D.A. (1965). The Management Theory Jungle Revisited. Advanced Management Journal 